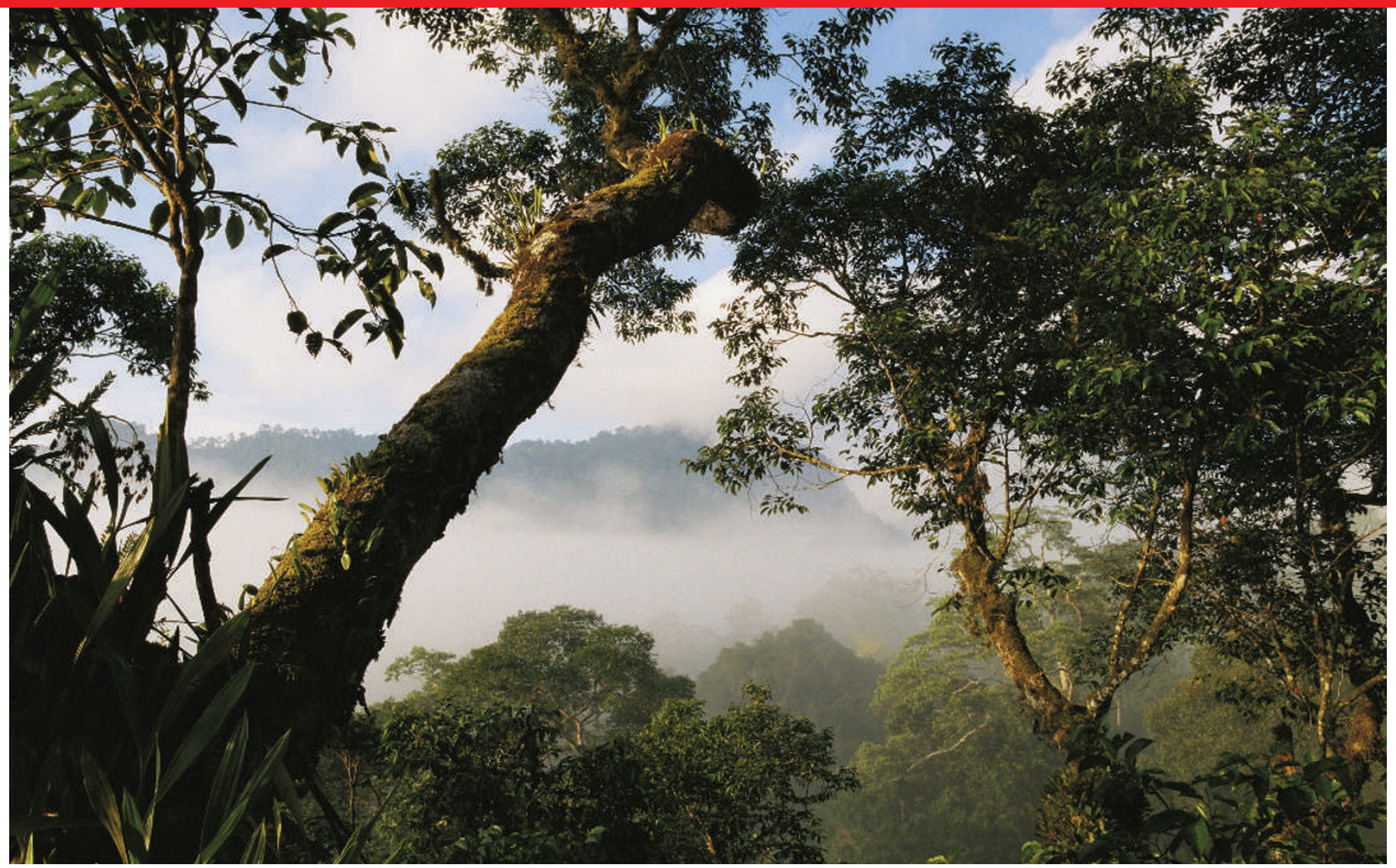

\title{
Logging: the new conservation
}

\section{Can a vast monoculture plantation be at the forefront of biodiversity protection? David Cyranoski} meets conservation biologists who hope to save species by making peace with the enemy.

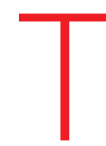

he forest in Borneo is usually a lush affair. But in the province of Sarawak, some forest regions have a striking monotony. Here, the skinny trees are all the same variety of acacia, some 20 metres high with short, jutting branches. The trees are spaced in regular rows, three metres apart.

Acacia mangium, a fast-growing species that is good for pulp and paper, is not native here. But at these nurseries on the Malaysian part of Borneo, 70,000 hectares of forest have been razed and replaced with a monoculture of acacias, grown at a rate of 3 million seedlings a month. Grand Perfect, a consortium owned jointly by three local timber companies, eventually plans to cover a few hundreds of thousands of hectares like this. The acacias will grow for just seven years before being harvested. Eventually, 30-tonne trucks will come every few minutes to carry away 3.5 million tonnes of wood a year.

This factory-like image is not what an environmentalist might call conservation. But many scientists are calling it the future of biodiversity protection. It is Grand Perfect's Planted Forests Project, a 490,000-hectare experiment in which just under half the land is set aside for logging, around a third for conservation and the rest for use by indigenous groups. In this unusual mosaic, customary foes - tim- ber companies, conservation biologists and local tribes - are working together to create a forest-management scheme that can meet all their respective needs. Each group has much to gain, or lose. For conservationists, the project's land is a precious piece of southeast Asia's famously biodiverse tropical forest, an important 'hotspot. Globally, tropical rainforests are disappearing at a rate of 12 million hectares a year. The Sarawak government, which commissioned and funds the project, and the timber companies that it has contracted, stand to gain tens of millions of dollars, if not more. Those living in the forest want to preserve their right to roam, hunt, fish and farm, and are being promised infrastructure and employment.

Rob Stuebing, a herpetologist who is the

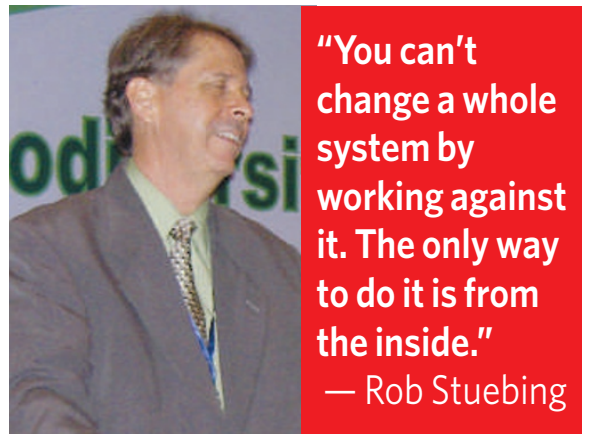

head of Grand Perfect's conservation division, is in the uncomfortable position of trying to reconcile these demands. It requires careful diplomacy. He argues with the loggers and pleads with the locals. He also deals with conservationists and fellow scientists, some of whom share his excitement about this new approach. Others charge that the effort is just an attempt to put an environmentally friendly gloss on a typical logging project.

Stuebing's greatest challenge will be to prove the sceptics wrong. He needs to show that biodiversity can be preserved within an area devoted mostly to a non-native monoculture, something that has never been proved before (see 'Tree swap'). As a conservation biologist taking up a position with a timber company, is Stuebing shaking hands with the devil? "I had misgivings at first," says Stuebing. "But you can't change a whole system by working against it. The only way to do it is from the inside."

Stuebing is a 30-year veteran of Malaysia's natural history who also has experience in the timber industry. He is tall, lean and seems more comfortable dressed for the field than in the suit and tie that his current job sometimes demands. He also has little patience for the most idealistic of his critics, who say that true conservation would be to enforce a hands-off policy. Since he joined Grand Per- 
fect in October 2004, Stuebing has moved fullspeed ahead on his mission: an inventory of the wildlife in the massive planted forest zone and coordination with the timber companies on a foresting strategy that protects, however imperfectly, what he finds. The plantations were started in 1996 without any biodiversity project in place, and some critics have said that the inventory is starting tens of thousands of hectares too late.

In January, Stuebing held a conference called Biodiversity Conservation in Tropical Planted Forest in Southeast Asia. Held in Bintulu, a coastal town 45 kilometres from the inland planted forest zone, the meeting was the first opportunity for all interested parties to discuss the future directions of his project and work out how to assess its progress. Some 70 naturalists, taxonomists and conservation biologists as well as representatives from the timber companies and the government attended the conference. The Sarawak chief minister, Pehin Sri Haji Abdul Taib Mahmud, called it a "dream come true for Sarawak's forest and biodiversity conservation" and, in grand ceremonial fashion, planted the plantation's 88 millionth tree. The local authorities love the scheme because they can make money from the land and still feel good about conservation.

\section{Chop and change}

Like many lush tropical forests, much of the area allocated to the planted forest zone is already 'disturbed'. For centuries, indigenous groups have chopped up parts of the forest to make room for farmland. Large-scale industrial logging, starting some 40 years ago, took a greater toll. Original 'old-growth' forest occupies at most $20 \%$ of the area; what has grown back on the disturbed land is called secondary forest.

The idea that these forests are already degraded and will continue to change is an important, and controversial, one. Some experts say that trying to return biodiversity to some ideal past era is unrealistic. Jianguo $\mathrm{Wu}$, a specialist on sustainability at Arizona State University in Tempe, opened the meeting with an appeal to consider forests as something to be used for sustainable development rather than as a static entity. Others vehemently disagree, and say that in the past five or ten years the degradation has become a frequently used excuse to convert forests to plantations in Malaysia and Indonesia. "All the forests need is some rest," said one silviculturist who did not want to be named.

Everyone agrees that there are limits to what can be called biodiverse. On the other side of the highway from one of the acacia plantations lies a wasteland of terraced, orangeish soil - the scar of an oil-palm plantation. Malaysia is the

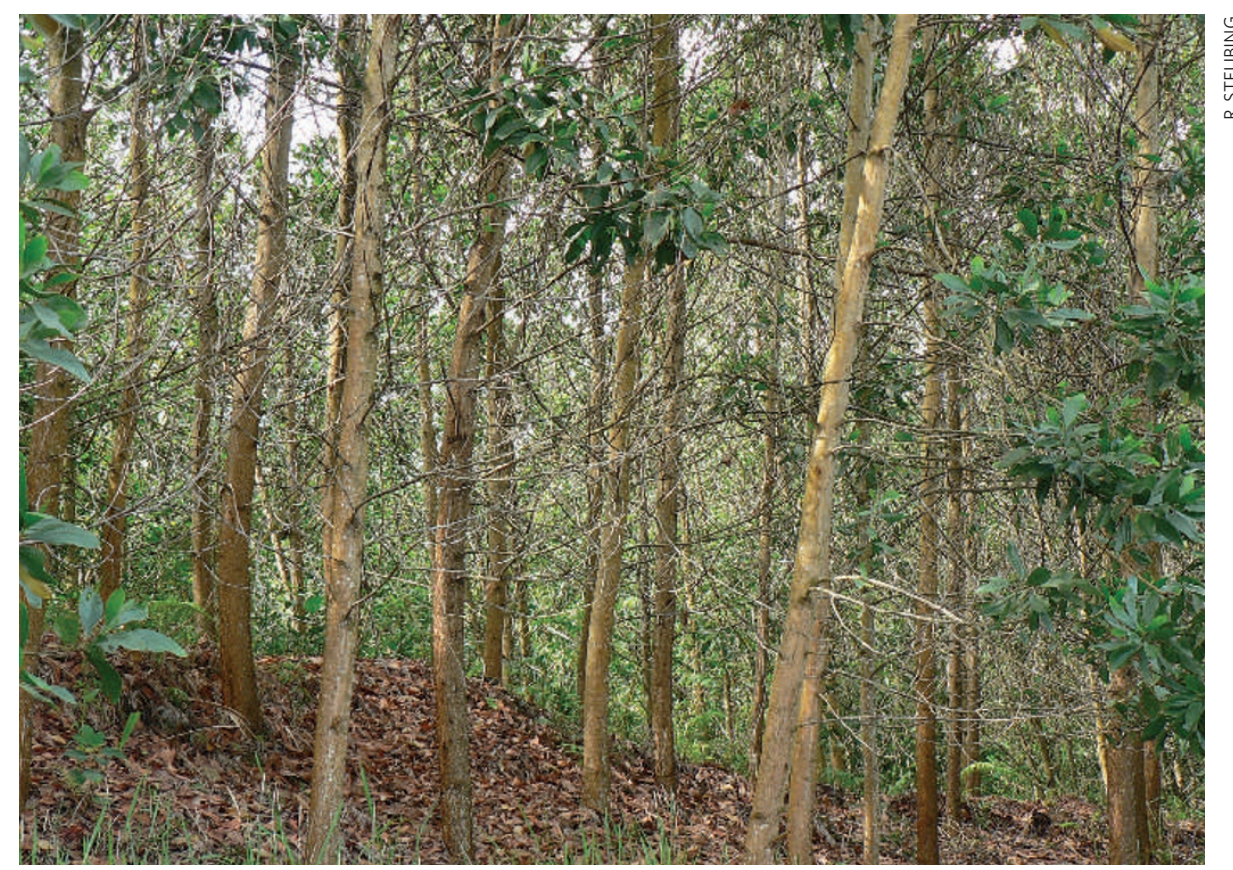

The Planted Forests Project will mingle pockets of acacia trees (above) with existing tropical forest.

number one producer of oil palm, but this type of forestry is the worst-case scenario for the conservationists. While Hollywood stars talk up the environmental friendliness of biofuels such as palm oil, here, the plants that produce them are demonized because they leave little room for anything else to live. If nothing else, everyone hopes that the acacia plantations will be more forgiving to their environment.

But what is at stake? Borneo is home to some 1,300 known mammals, birds, frogs, snakes and lizards, about two-thirds of which are thought to be in and around the planted forest zone. Stuebing estimates that around $20 \%$ of the mammals and perhaps $60 \%$ of the amphibians are endemic, existing here and nowhere else. But these are approximations. The area has never been explored thoroughly, and the project's first priority is to take an inventory. As the loggers move in, there is a sense of urgency because many species could be lost before they are ever discovered.

At the conference, Stuebing called on all scientists to help identify the forest's wealth of organisms. Many, keen to expand their collections, have already taken up the call and their initial forays have turned up plenty. Jaap Vermeulen of the National Herbarium of the Netherlands at Leiden University has found 83 species of snail in a region called Bukit Sarang, part of the area devoted to conservation. "Thirty-one of these are new to science. It is exceptional, a really hot piece of real estate," he says.

Stuebing's challenge is to use the conservation zones, which are marbled into the plantations, to simulate a more extensive forest that has room for large mammals to roam. When local populations go extinct, larger forests also support 'meta-
populations' that can repopulate them. Stuebing works with the loggers to designate corridors — such as 50 to 500-metre-wide swathes of land alongside rivers - that are crucial for mobility of many species. Maintaining the survival of rare, symbolic flagship species, such as hornbills, tufted ground squirrels and gibbons, would be a huge success. But Stuebing is not sure that his corridors will be long or wide enough.

\section{Support structures}

The biggest question mark, and one that could be crucial to the success of the entire venture, is whether the acacias will support wildlife. Frogs, rats, squirrels, ungulates and carnivores seem to do well in acacias because they like the food and breeding sites. Understory birds, snakes, lizards and bats, however, are less happy. Bill McShea, an ecologist at the Conservation and Research Center of the Smithsonian National Zoological Park in Front Royal, Virginia, uses camera trapping to follow large mammals. $\mathrm{He}$ found that about two-thirds of the 39 species he had identified in the local 'disturbed' forest 
were also living in the acacias. "So does [this result] mean they are running for their lives? Or are they living there stably? It is impossible to tell right now," he says. And even if the animals are settled, no one knows what will happen when the acacias are harvested after seven years.

Stuebing admits that, with only $2 \%$ of Grand Perfect's total budget, the conservation programme is a relatively small concern for the timber companies, so working to influence them is crucial. But the companies are coming under increasing pressure from their buyers to certify that pulp and paper exports come from rain forests that are managed sustainably. Such concerns give Stuebing more leverage to fight for wider corridors. Grand Perfect says that it is also trying to change its logging practices by, for example, using an elevated cable system to extract logs rather than dragging them on the ground and eroding the soil.

\section{Lap of luxury}

Grand Perfect's efforts to integrate scientists - and its construction of relatively luxurious field stations - impressed the conservation biologists who attended the Bintulu meeting. "Never before has a commercial enterprise spent so much time ensuring that there is a biodiversity programme in place," says the Earl of Cranbrook, chairman of the International Trust for Zoological Nomenclature and a 50-year veteran of the southeast Asian natural-history scene.

Because the acacia plantations are very

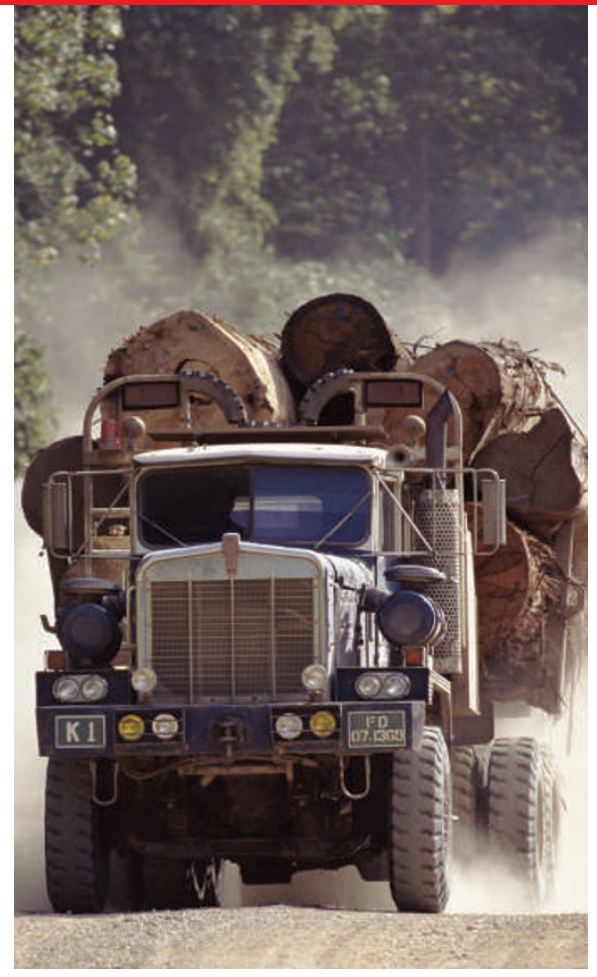

Cutting down: large areas of primary forest are being cleared to make way for acacia plantations.

productive, some argue that they will also relieve the pressure to cut into other, more pristine forest. Warren Ellis, who represented Grand Perfect's logging division, told the meeting that a hectare of acacia plantation produced more wood than ten hectares of forest that had been logged and had then regrown naturally. Hans ter Steege, a plant ecologist at the National Herbarium of the Netherlands in Utrecht, is also optimistic. "I would approach the project with a positive attitude. All the right ingredients - social, economic and ecological — have been addressed."

\section{Tree swap}

Plantations in biodiversity zones do not usually take pains over conservation. There are a few examples in which survival of native species has been measured, but their results have been discouraging.

The Jari project in Brazil is one of few precedents on the same scale as Malaysia's Planted Forests Project. In the 1960s, US billionaire Daniel Ludwig purchased 1.7 million hectares of almost undisturbed forest and used about $10 \%$ of it to plant trees for paper. Ludwig chose Gmelina arborea - a nonnative, fast-growing tree - but it turned out that it did not grow well in the Amazon and was replaced with eucalyptus.
At the time, the project did not have a biodiversity programme in place, but in 2003, Carlos Peres, an expert on tropical forest ecology at the University of East Anglia in Norwich, UK, launched one with the Emílio Goeldi Museum in Belem, Brazil. Peres's group looked at more than 1,450 species, but with disappointing results. "Suffice it to say that, for the 16 taxonomic groups of plants, vertebrates and invertebrates that we sampled, primary forests were irreplaceable in terms of the proportion of species that can be retained," he says.

On the Tiwi islands

in Australia's Northern Territory, native eucalyptus has been replaced with Acacia mangium on a much smaller scale than that of the Planted Forests Project.

But the plantation has displaced much of the native wildlife. "The environmental consequences have been profound," says John Woinarski, from Australia's Department of Natural Resources, Environment and the Arts, and an author of a study into the project's effects (R. Firth et al. J. Biogeogr. 33, 1820-1837; 2006).

In particular, most of the mammals have made little use of the plantation, including species such as the brushtailed rabbit-rat and Butler's dunnart, which are considered threatened or vulnerable. D.C.
But not everyone is happy. Some scientists have accused the project of failing to take into account a key factor - the incredible diversity of the indigenous trees. Peter Ashton, a retired expert on the forests in Sarawak, points out that the Sarawak lowlands contain some 3,000 species of tree and that the trees support the insects and microorganisms that account for the vast majority of the forest's biodiversity.

\section{Token gestures}

Conservationists have also become cynical of nods to their cause by loggers. A 2006 report by the Center for International Forestry Research in Indonesia found that some companies are recruiting billions of dollars from investors by saying that they have sustainable sources to feed their pulp mills when, in reality, they are relying on natural forests in Indonesia for most of the supply. Gustavo Fonseca, the chief conservation and science officer at Conservation International in Arlington, Virginia, questions whether the proportion of land given over to native forest in the project is high enough, and says that road-building and increased fire-hazards "may create impacts far beyond [those of the] plantation". Fonseca also notes that $A$. mangium, although not thought to be invasive, has shown signs of spreading spontaneously in the Caribbean.

As yet, there is no pulp mill, and the logging will probably not start in earnest for several years. By then, Stuebing and his colleagues will have a better idea of whether their patchwork experiment will work. If it does not, the acacia harvesting will still proceed. The data obtained could still be of use, because they will probably be the best record yet of how acacia plantations affect biodiversity, something that is important for the many other plantations in Sarawak and elsewhere in Borneo. And Stuebing looks on the bright side: "At the very least we have done some good science."

The conservationists may not share his rosy outlook, but they - and the loggers they traditionally eyed with aversion - may also gain a new perspective. "Some romantics, like myself, thought that all was lost with the cutting of the rainforests," says Robert Inger of the Field Museum in Chicago, who has worked in Borneo for decades. Like most at the conference, Inger now recognizes that demand for timber means the inevitable end of many species. He has watched frogs try to familiarize themselves with their new environment in the acacias and is hopeful that they have set up shop there. "We may have to look at the forests again with less romantic eyes," he says.

David Cyranoski is Nature's Asia-Pacific correspondent.

See Editorial, page 583. 